\title{
Events in Space
}

\author{
Amy Rose Deal \\ University of Massachusetts, Amherst
}

\section{Introduction: space as a verbal category}

Many languages make use of verbal forms to express spatial relations and distinctions. Spatial notions are lexicalized into verb roots, as in come and go; they are expressed by derivational morphology such as Ineseño Chumash maquti 'hither and thither' or Shasta ehée 'downward' (Mithun 1999: 140-141); and, I will argue, they are expressed by verbal inflectional morphology in Nez Perce. This verbal inflection for space shows a number of parallels with inflection for tense, which it appears immediately below. Like tense, space markers in Nez Perce are a closed-class inflectional category with a basic locative meaning; they differ in the axis along which their locative meaning is computed. The syntax and semantics of space inflection raises the question of just how tight the liaison is between verbal categories and temporal specification. I argue that in view of the presence of space inflection in languages like Nez Perce, tense marking is best captured as a device for narrowing the temporal coordinates of a spatiotemporally located sentence topic.

\section{The grammar of space inflection}

There are two morphemes in the category of space inflection, cislocative (proximal) $-m$ and translocative (distal) - $k i$. Space inflection is optional; verbs without space inflection can describe situations that take place anywhere in space. ${ }^{1}$ I will refer to the members of the space inflection category as space markers.

Space inflection is a suffixal category in Nez Perce, and squarely a part of the "inflectional suffix complex" or tense-aspect-mood complex of suffixes. As$\mathrm{pect} / \mathrm{mood}$ is always marked in Nez Perce (with the exception of certain copulative constructions $^{2}$ ). The aspectual/modal categories are imperfective, habitual, perfect, perfective, future and imperative. In the imperfective and habitual aspects, pastness

Many thanks are due to my Nez Perce teachers Cecil Carter, Florene Davis and Bessie Scott, and to Angelika Kratzer, Chris Davis and the many helpful audience members at SALT. Field research was supported by the National Science Foundation under Grant No. BCS-0418311 (summer 2007) and by the American Philosophical Society (summer 2008). In addition, this material is based upon work supported under a National Science Foundation Graduate Research Fellowship.

${ }^{1}$ No special semantics has been noted for clauses that lack a space marker. In this Nez Perce contrasts with Upriver Halkomelem, where the absence of space marking yields an irrealis interpretation (Wiltschko and Ritter 2005).

${ }^{2}$ Aspectless copular root we is sometimes noted in place of wees 'I am/you (sg.) are', where -s is aspectual; consultants do not perceive a difference between the two forms. Also noted are cases such as (i), where a noun is inflected as a stative verb without overt verbalizing or aspectual morphology. 
is obligatorily indicated by tense suffixes. The perfect and the perfective aspects themselves contribute pastness and disallow tense suffixes. ${ }^{3}$

Future is indicated by either of two suffixes, one of which behaves like an aspect; we will see more on the future below. Present tense is unmarked.

When aspect, tense and space inflection are all present, space inflection occurs between aspect and tense. The following examples are drawn from various Nez Perce corpora. ${ }^{4}$



(i) ke kona hi-tex̂pé'em REL there 3SUBJ-plain where there are plains (Aoki and Walker 1989: 395)

These cases are exceptions to the otherwise strong generalization that all Nez Perce verbs bear aspect/mood suffixes.

${ }^{3}$ With an eventive verb in the perfect, speakers reject non-past readings. An exception is when the clause contains complementizer $k e$, which gives an "optative" future reading for the perfect.

(i) Context: the teacher annouces that three girls are needed to say the Nez Perce language pledge in front of the class. A student replies:

'iin ke-x ku-s

1SG REL-1SG do-PCT

Let me do it!

The perfective always contributes pastness. There is also evidence that it requires culmination of an event (by contrast to the perfective in Salish languages; Matthewson 2004, Bar-El 2005):

(ii) sawlakay'k-sa-qa toyam-x kaa wiclem-ne drive-IMPERF-REC.PAST top-to and fail-PERF

I was driving to the top but I failed (didn't get there)

(iii) \# sewlekey'k-e toyam-x kaa wiclem-ne drive-PERF top-to and fail-PERF

Comment: "You're saying you did drive to the top, so you can't say then you failed."

${ }^{4}$ I would like to thank Phil Cash Cash for providing me with a searchable version of the Aoki and Walker 1989 corpus.

Abbreviations in glosses are: CIS cislocative, TRANS translocative, IMPERF imperfective aspect, PERF perfective aspect, HAB habitual aspect, PCT perfect aspect, PRT particle, PART participle, APPL goal applicative, FUT future, REC.PAST recent past tense, REM.PAST remote past tense, ERG ergative case, OBJ objective case, LOC locative case, $3 / 3$ third person subject and third person object portmanteau verbal agreement, 3OBJ 3rd person object agreement, 3SUBJ 3rd person subject agreement, 3POss 3rd person possessor subject agreement (marker of subject possessor raising), S.PL plural subject agreement. 
You didn't give anything (Aoki and Walker 1989: 188)

yô̂ kala 'ee ime-né hi-xyóo-s-in-m-qa kaa

DEM just you you-OBJ 3SUBJ-come-IMPERF-S.PL-CIS-REC.PAST and

nuun ip-née 'a-xyóo-s-in-m-qa

we he-OBJ 3OBJ-come-IMPERF-S.PL-CIS-REC.PAST

It's just that they were coming here to you and we were coming here to him (Phinney 1934: 230)

qó'c timáayi-na 'aw-'náh-wayik-sa-nqa-qa

still girl-OBJ 3OBJ-carry-move.across-IMPERF-TRANS-REC.PAST

I was still moving the girl away across (Aoki and Walker 1989: 455)

hi-wehye-c-in-ki-ke

3SUBJ-go-IMPERF-S.PL-TRANS-REM.PAST

They were going away (Aoki and Walker 1989: 292)

The fact of their position between aspect and tense, combined with the small number of space markers and the regularity and productivity of their semantic contribution, strikes me as strongly in favor of an inflectional and not derivational approach to space inflection. ${ }^{5}$

The morphology of Nez Perce space markers is also likely to be informative as to their syntactic position. Nez Perce suffix order is in general well-behaved; valence-changing morphology (such as applicatives) falls inside aspect marking, which in turn falls inside tense marking. Space inflection intervenes between aspect and tense, as we have seen. This suggests a structure like the following: ${ }^{6}$

\section{$\mathrm{V}]_{V P}$ Applicatives $]_{v P}$ Aspect $]_{A s p P}$ Space $]_{S p P}$ Tense $]_{T P}$}

The distribution of space inflection is limited by aspect/mood, as shown in Table 1. In compiling this table I have drawn on work with Nez Perce speakers, recent grammatical descriptions (Aoki 1970, Rude 1985, Crook 1999) as well as an older missionary grammar (Morvillo 1891), which provides some forms that are not noted in later studies. These forms fill gaps that otherwise seem accidental, i.e. the lack of a recent past habitual cislocative and remote past imperfective translocative in the paradigms compiled by Rude (1985). ${ }^{7}$ All sources show the absence of

\footnotetext{
${ }^{5}$ Notably, in addition to space inflection, Nez Perce makes use of a quite large and semantically rich group of verbal derivational affixes, some of which mark spatial notions. These do not compete with space markers. Examples are $c u$ - 'underneath', sike- 'in the distance', 'êxew- 'side by side' (Aoki 1970: 84-86).

${ }^{6}$ There may also be an agreement projection between AspP and SpaceP to accomodate subject number inflection, which appears here in the imperfective and habitual aspects and in the imperative. In other inflectional classes, subject number agreement is prefixal.

${ }^{7}$ Morvillo gives recent past habitual cislocative in tima-nkámka, presumably 'iin tim'anqamqa 'I used to write nearby'. He also gives a form that is plausibly the imperfective remote translocative, time-zenkike (tim'ecenkike, 'a while ago, I was writing far away'). This form clearly includes imperfective ce (Morvillo's ze), though it is surprising that it is not time-zenkine (tim'ecenkine), with the nasal of the remote past suffix visible. Nevertheless, this form of the inflectional suffix complex is independently attested in the Aoki and Walker (1989) corpus, e.g. as in (6).
} 


\begin{tabular}{ll|cc} 
aspect & tense & CIS & TRANS \\
\hline imperfective & present & $\mathrm{Y}$ & $\mathrm{Y}$ \\
& recent & $\mathrm{Y}$ & $\mathrm{Y}$ \\
& remote & $\mathrm{Y}$ & $\mathrm{Y}$ \\
\hline habitual & present & $\mathrm{Y}$ & $\mathrm{n}$ \\
& recent & $\mathrm{Y}$ & $\mathrm{n}$ \\
& remote & $\mathrm{Y}$ & $\mathrm{n}$ \\
\hline perfect & - & $\mathrm{Y}$ & $\mathrm{Y}$ \\
perfective & - & $\mathrm{Y}$ & $\mathrm{Y}$ \\
future & - & $\mathrm{Y}$ & $\mathrm{n}$ \\
imperative (mood) & - & $\mathrm{Y}$ & $\mathrm{n}$
\end{tabular}

Table 1: The distribution of space marking, aspect and tense

translocative forms for the habitual aspect, the imperative and the future. At present I do not have an explanation for why the distribution of the translocative is more limited than that of the cislocative.

While space inflection (particularly translocative) is limited depending on aspect, it does not appear to be sensitive to the meaning of the verbal predicate itself. In particular, Nez Perce space inflection is not sensitive to the distinction between stative and dynamic predicates. ${ }^{8} 9$

On a predicate that defines a path, the space markers generally locate the end of the path as near (cislocative) or far (translocative) from the utterance location.

meet'u téemux 'e-wehye-m

but footprint 3POSS-come-CIS

But his footprints lead this way (Phinney 1934: 219)

(9) kawo' heenek'e hi-q'uyim-cen-ki

then again 3SUBJ-climb-IMPERF-TRANS

He climbed farther up. (Aoki and Walker 1989: 12)

'iskit hi-ku-séen-ki

trail 3SUBJ-go-IMPERF-TRANS

The trail goes that way (away from the speaker) (Aoki 1994: 243)

The tendency of these markers to locate the endpoint of a path-defining eventuality, as opposed to the beginning or a point in the middle, is apparently not absolute, as cases like the following show:

\footnotetext{
${ }^{8}$ In this sense previous descriptions have been incomplete, in that they describe space markers as indicating the direction of a motion event. Rude (1985) calls them "directionals". Crook (1999) writes that "the cislocative generally indicates motion or action oriented towards the speaker and the translocative motion or action oriented away." However, Rude notes that "the cislocative very often occurs where it would seem to make no sense whatever as "hither"' (p. 49), citing a number of instances on non-path-defining verbs.

${ }^{9}$ This contrasts with the space marking system of Abaza (Northwest Caucasian), where space marking is limited to dynamic predicates (O'Herin 2002).
} 
(11) walíms sis 'inpí-m

W mush take-CIS

Walims, take mush from here! (Phinney 1934: 92) ${ }^{10}$

inanq'o'c muqs-ni-m, wetemeyleki-m

me.first swallow-IMPER-CIS, inhale-CIS

Swallow me first, inhale me! (Coyote's challenge to the monster; Phinney 1934: 20)

(13) niwíhne-m

leave-CIS

Leave! (Aoki 1979: 10)

These clauses are all imperatives. (As noted in Table 1, the translocative is not found in imperatives.) Note that the cislocative retains its first-person-oriented character in these cases; they still locate part of the event as proximal to the speaker. However, it appears that the beginning and not the end of these events is located as proximal to the speaker, making them compatible with motion away from the speaker's location. ${ }^{11}$

In addition to its use on path-defining predicates, space inflection is found on non-path-defining predicates. In these cases it generally locates the event/state as proximal (cislocative) or distal (translocative) from the speech location; in cases like $(14 \mathrm{c})$ and $(15 \mathrm{c})$ it seems to locate the subject of the copular verb. ${ }^{12}$

(14) Non-path-defining predicates: cislocatives

a. hi-'yoxo'-yo'-kom 3SUBJ-wait-FUT-CIS

He will wait here

b. kine hi-weqi- $\emptyset$-me here 3SUBJ-rain-PCT-CIS

It rained here.

c. kalá hawlapawláp hi-wé-m laymíwt just spirited 3sUBJ-be-CIS youngest

The youngest one was very spirited (Phinney 1934: 221)

(15) Non-path-defining predicates: translocatives

a. ku’ málack'iw kálo’ hi-wíi-cen-ki UNSURE several.nights just 3SUBJ-cry-IMPERF-TRANS

It kept crying for several days (Aoki and Walker 1989: 537)

\footnotetext{
${ }^{10}$ This gloss is based on Phinney's word-by-word gloss; the verb is glossed as 'take from here'. Phinney's free translation is 'Take for yourself some mush'.

${ }^{11} \mathrm{Cf}$. Q'eqchi' (Mayan) particle čaq, which always locates the initiation point of an event spatially, not the endpoint (DeCormier 1979). Thanks to Roger Schwarzchild for bringing this case to my attention.

${ }^{12}$ This meaning for space inflection recalls Kratzer (1995)'s proposal that tense may in some cases locate a nominal argument in time.
} 
b. hi-weqi- Ø-ki waykiki

3SUBJ-rain-PCT-TRANS Waikiki.Hawaii

It rained in Waikiki.

c. qó'c hi-wée-ki

still 3SUBJ-be-TRANS

He is still there (Aoki 1994: 843)

A final comment on the grammar of space inflection concerns what space inflection is not: it is not object agreement. Cislocative marking in particular is often translated by verbs with first person objects; first person object agreement is not overtly marked on verbs. ${ }^{13}$ However, it does not seem correct to analyze cislocative as first-person object agreement. Crucial data comes from complementizer agreement. A real first person object in a relative clause triggers agreement on the relativizer $k e$ :

míne híiwes háama ke-x ko-ním ha-ak-ca-qa kii

where is man rel-1SG DEM-ERG 3SUBJ-See-IMPERF-REC.PAST this

méywi

morning

Where is the man who saw me this morning?

The cislocative (with or without the first person object meaning) does not trigger this inflection:

(17) kalá ke-m ku'ús hin-ú'-kum tax̂c kaa ku'ús kiy-ú' just rel-2SG thus say-FUT-CIS PRT then thus do-FUT

I'll do what you tell me. (Phinney 1934: 5)

(18) tim'úune 'eweeke ke yox páa-myaamolna-'nya-m bow was REL DEM 3/3-be.fond-APPL-CIS

It was a bow which he (coyote) was fond of his (his child's) (Aoki and Walker 1989: 16)

(19) pee-suuk-s yox ke ha-'ac-im 3/3-recognize-PCT DEM REL 3SUBJ-enter-PCT-CIS

She recognized the one who just came in

In these cases, agreeing complementizers fail to register a first person object. Thus a closer translation of these cases may use 'here' instead of a first person object, e.g. (17) may better be rendered 'I'll do what you say here'.

To summarize the basic grammar of space inflection in Nez Perce, I have argued that space inflection is (a) inflectional; (b) syntactically located between aspect and tense; (c) not sensitive to verb class; and (d) not to be confused with object agreement. We can now turn to some of the semantic issues involved in the analysis of space marking.

\footnotetext{
${ }^{13}$ This is part of a larger generalization that overt person agreement in the verbal system is for third persons only. First and second person objects participate in number agreement with the verb, and may agree with certain complementizers and clause-initial particles, as discussed below.
} 


\section{Space inflection and tense inflection}

Space inflection is in many ways similar to tense inflection. Like tenses, space markers are closed-class, inflectional morphemes with a basic meaning of locating events. ${ }^{14}$ Where tense gives the "grammaticalized expression of location in time" (Comrie 1985), space inflection gives parallel expression in the realm of space. Space markers are deictic as tenses are; they locate eventualities with respect to the utterance location, just as tenses locate eventualities with respect to the utterance time. ${ }^{15}$ In addition, space markers and tenses seem to encode the same distinctions in Nez Perce. Cislocative indicates nearby spatial location, where recent past indicates nearby temporal location in the past; translocative indicates distal spatial location, where remote past indicates distal temporal location in the past. Finally, the position of space inflection provides a parallel with tense; both appear immediately above aspect. ${ }^{16}$

\subsection{Independence of space inflection and tense (and one case of dependence)}

Space inflection and tense in Nez Perce typically function independently to specify the spatiotemporal coordinates of an event. Both relate an event to the utterance situation. (The exception to this is in the $u$ ' future, as discussed below.)

$$
\text { kúu'weet pa-payn-óo-san-ki sikís-ne }
$$
perhaps 3/3-come-APPL-IMPERF-TRANS nest-OBJ Perhaps he is reaching the nest (Aoki and Walker 1989: 12)

a. translocative: distant space w.r.t. to utterance location

b. present tense: present time w.r.t. to utterance time

hi-waqi-sa-m-qa lepwey kex kaa iin weke
3sUBJ-rain-IMPERF-CIS-REC.PAST Lapwai.ID when.1SG I was
tatxinma
Moscow.ID
It was raining here in Lapwai when I was in Moscow
a. cislocative: local space w.r.t. utterance location
b. recent past: past time w.r.t. to utterance time

Independent coordinate specification is particularly clear in (21). Here the cislocative on the main verb indicates that the rain event's location is close to the utterance

\footnotetext{
${ }^{14}$ Status as inflectional, rather than derivational, is noted as a criterion for tenses by Shaer (2003).

${ }^{15}$ This holds in matrix clauses. Embedded clauses and the issues they raise are discussed in $\S 5$.

${ }^{16}$ This finding could also be taken to provide a parallel between space inflection and aspect, as they both occur immediately below tense. However, space inflection does not display any of the key characteristics of aspect (as opposed to tense) laid out by Tonhauser (2006). Notably, there are no verb class restrictions and no encoding of state changes. Space markers may coöccur with aspect, but aspectual markers cannot coöccur.
} 
location (the speaker's present location). The locative phase lepwey further specifies that the rain event took place in Lapwai. However, the when-clause indicates that at the time the rain occurred, the speaker was not in Lapwai but in Moscow, 40 miles to the north. The cislocative relates the event's location to the utterance location, i.e. the present location of the speaker, and not to the location of the speaker at the time that the event occurred. Space and time are calculated independently from the coordinate of utterance.

Independent coordinate specification is also visible in futures formed with future marker tet'ee, frequently translated as 'gonna'. This future marker occurs below imperfective aspect. In the following case, as in (21), the cislocative relates the event location to the utterance location, the location of the speaker at the present, and not the location of the speaker at the future time.

kine hi-'yoxoo-tat'aa-sa-m kex kaa wek-u' Payniwas-pa here 3SUBJ-wait-GONNA-IMPERF-CIS when.1SG be-FUT Payniwas-LOC He's gonna wait here while I'm at the Payniwas Café

a. cislocative: local space w.r.t. to utterance location

b. 'gonna' future: future time w.r.t. to utterance time

The one exception to independent coordinate specification of which I am aware occurs with the future $u^{\prime}$ (and phonologically conditioned variants $o^{\prime}, y u^{\prime}, y o$ '), and concerns a special cislocative form -kum (cf. productive cislocative $-m$ ). ${ }^{17}$ This is the only form of space marking that occurs with the future $u$ ' and the future $u$ ' is the only verbal form with which the kum cislocative occurs. ${ }^{18}$ The future+cislocative combination $u^{\prime}$-kum requires that the event location be proximal to the speaker's location at the future time, not necessarily to the speaker's present location. Thus (23) is judged contradictory:

$$
\begin{aligned}
& \text { \# kine lepwey-pe hi-weqi-yu'-kum meet'u iin wek-u' } \\
& \text { here Lapwai.ID-LOC 3SUBJ-rain-FUT-CIS but I be-FUT } \\
& \text { tatxinma-pa } \\
& \text { Moscow.ID-LOC } \\
& \text { It will rain here in Lapwai but I'll be in Moscow (40 miles north) } \\
& \text { Consultant comment: That wouldn't happen! } \\
& \text { a. cislocative: local space w.r.t. to speaker's future location } \\
& \text { b. } u \text { ' future: future time w.r.t. utterance time }
\end{aligned}
$$

In (23) the kum cislocative requires that the rain event be proximal to the speaker's location at the future time. Independent adverbial(s) kine lepwey-pe 'here in Lapwai' further specifies that the rain will take place at the location of utterance, Lapwai. It follows that the speaker will be in or very near Lapwai during the rain event.

\footnotetext{
${ }^{17}$ The $u$ ' future is by far the more common future form in Nez Perce. For present speakers, $u$ ' behaves like an aspect; it does not combine with other aspects and its order with respect to other suffixes is as expected for an aspectual marker. The semantic difference between futures in $u$ ' and those in tet'ee is the topic of ongoing research.

${ }^{18}$ The kum form may be decomposable into $k u+m$, where $m$ is the regular cislocative. The $k u$ morph may be related to the verb 'to go' or the light verb, both of which are $k u$.
} 
However, the when-clause specifies that the speaker will be in Moscow, 40 miles north, at the time of the rain. In order for the prediction expressed by this sentence to come true, the speaker would have to be simultaneously in Lapwai and in Moscow at the time of the rain. Accordingly, the sentence was rejected. So too was the version of (24) with the space marker (by contrast to (22), nearly identical but for the choice of future and space marker). ${ }^{19}$

kine hi-'yoxo'y-o'(\#kom) ke-x kaa 'iin wek-u' Payniwas-pa here 3SUBJ-wait-FUT-\#CIS REL-1SG then I be-FUT Payniwas-LOC

He will wait here while I'm at the Payniwas Cafe

We thus find two patterns of interaction between space marking and temporal marking in Nez Perce. Productive cislocative and translocative marking locate events with respect to the utterance location, just as tenses do; space inflection and tense inflection independently specify the coordinates of an event. The restricted cislocative kum, on the other hand, locates events with respect to the speaker's spatial coordinate at a particular time.

\subsection{The formal treatment of space inflection and tense}

The parallels between space inflection and tense, together with their independence in the general case, suggest that whatever machinery we adopt to account for tense may be fruitfully extended to account for space inflection. Recent work on tense has largely settled on a sortal analysis, where times are represented as a special sort of individuals. Such a view allows for a referential view of tenses (i.a. Quine 1960: $\S 36$, Partee 1973), or a view where tenses are quantifiers over times in the object language (i.a. van Benthem 1977, Kusumoto 2005). If we adopt this type of view for space inflections, we might adopt a special type $p$ for individuals in the sort of spatial positions/locations; such a move has been suggested by Kaplan (1989) as well as Kracht (2002).

Turning to a sortal view of space marking requires a careful reappraisal of the other elements on the clausal "spine" - verb, aspect and tense. If space markers contribute spatial variables or quantify over spatial arguments, we must assure that these can serve as appropriate arguments to other functors. We turn next to the question of this composition.

\footnotetext{
${ }^{19}$ Evidence from texts also shows the absence of independent coordinate specification with the $u$, future. The following sentence is told by a hunter to his wife; the location where she will meet him with water is not close to their present location, but is close to his future location.

(i) 'inee'-wewkun-yu'-kum kuus carry-meet-FUT-CIS water You will meet me with water (Phinney 1934: 153)
} 


\section{Sorts and situations}

In appearing immediately above aspect in Nez Perce, space inflection occupies a syntactic slot in many languages reserved for tenses; in intervening between tense and aspect, it interrupts what would seem to be a dedicated structure for considerations of temporal relations. These temporal relations have been argued to involve three times: the time of the event, the time of speech and a third time first brought to light as Reichenbach (1947)'s "reference time". In influential work, Klein (1994) argued for a conceptualization of this third time as "topic time", the time which an utterance is about. Aspect relates the event time to the topic time; tense relates the topic time to the utterance time. This model of tense and aspect was formalized by Kratzer (1998); here are her denotations for imperfective aspect and past tense.

(25) Imperfective viewpoint aspect:

$\lambda P \lambda t \lambda w \exists e[t \subseteq \tau(e) \& P(e)(w)]$

Past tense:

$\llbracket p a s t \rrbracket^{g, c}$ is only defined if $c$ provides an interval $t$ that precedes $t_{0}$. If defined, then $\llbracket p a s t \rrbracket^{g, c}=t$

Imperfective aspect takes as its argument a property of events, provided by the verb phrase. AspP denotes a property of times, which is saturated by tense. How is space inflection to be introduced into this picture?

We saw above that space inflection and tense inflection in Nez Perce serve very similar functions in providing coordinates with respect to the space and time of utterance. On a Kleinian picture, the temporal coordinate is the topic time, the time the utterance is about. The existence of a parallel category of space inflection suggests that whatever the sentence is about has a spatial profile as well as a temporal one. Space inflection locates one coordinate of the spatiotemporal topic and tense inflection locates the other. Following work in situation semantics, in particular Kratzer (2007), I will refer to the spatiotemporal topic as the topic situation. Encoding tenses and spatial inflections with respect to a topic situation that is part of the evaluation world obviates the need for a specially referential theory of tenses or space markers. Classic cases of "referential tense" like Partee's famous example I didn't turn off the stove (Partee 1973) derive their referentiality from making a claim about a particular topic situation; the tense itself merely provides the temporal coordinate for the referential topic.

We maintain, then, the Kleinian view that aspect provides a connection between an event and a topic. We will now take AspP to denote a property not of times but of situations, something more general. Tense and space inflection are formally situation modifiers, restricting the coordinates of the topic situation with respect to time and space respectively. ${ }^{20}$ The topic situation itself is represented via a situation variable in TopicP. In the denotations below, $\prec$ is the temporal precedence relation; $\sim_{t}$ and $\chi_{t}$ are temporal proximity and distance relations, respectively; $\sim_{s p}, \chi_{s p}$

\footnotetext{
${ }^{20}$ The denotations here compose with the clausal spine via Modification; it would also be possible to give slightly higher-typed denotations that compose via Function Application.
} 
are spatial proximity and distance relations, respectively; $s$ and $e$ are situation and event variables, respectively; $s^{*}$ is indexical to the utterance situation; and $\leq$ is a spatiotemporal inclusion relation.

Tenses

a. Recent past -qa: $\lambda s . s \prec s^{*} \& s \sim_{t} s^{*}$

b. Distant past -na: $\lambda s . s \prec s^{*} \& s \chi_{t} s^{*}$

Space inflection

a. Cislocative $-m: \lambda s . s \sim_{s p} s^{*}$

b. Translocative $-k i: \lambda s . s \chi_{s p} s^{*}$

The system is demonstrated for the verb form in (21), repeated in (29):

hi-waqi-sa-m-qa

3SUBJ-rain-IMPERF-CIS-REC.PAST

It was raining here

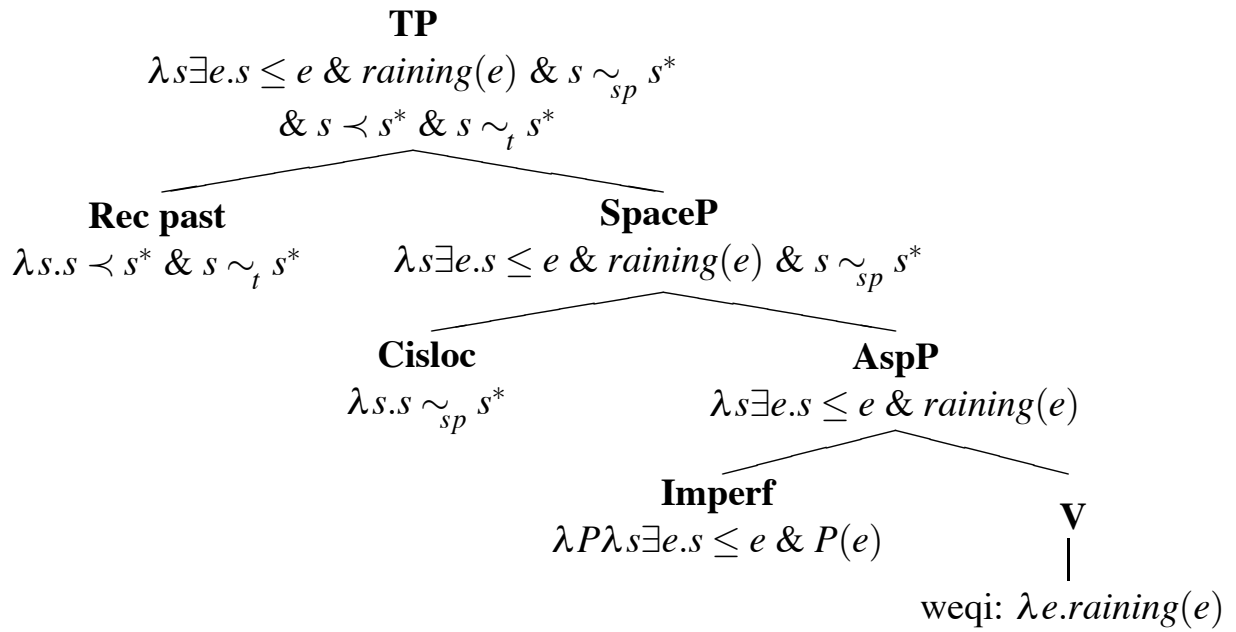

Because this approach treats space markers as situation modifiers, we do not need to make special stipulations or posit covert structure for cases where no overt space marker is seen. We can also deal nicely with patterns found in space marking systems beyond Nez Perce. For items like Q'eqchi' čaq, which may have a meaning of spatial location or of temporal location (DeCormier 1979; this is also the case for many English prepositions), we can adopt a denotation that encodes proximity or distance between two situations without specifying the relevant axis. We can also perhaps provide an explanation for the interaction of tense marking and space marking in Sanuma (Borgman 1990), a language where location is expressed in the verbal system only in the present tense, when tense marking is not overtly expressed. Space inflection and tense marking seem to be in competition for the same spot. ${ }^{21}$ It may be that Sanuma morphosyntax permits only one situation modifier per verb; when no tense is expressed, a space marker may be used instead. The

\footnotetext{
${ }^{21}$ While Sanuma verbal space marking seems to occupy the same position as tense inflection, Borgman's description suggests that the parallels may not be as strong as in the Nez Perce case.
} 
present tense interpretation of such clauses may be derived pragmatically from the absence of past or future marking.

\section{Space inflection in embedded clauses}

Embedding structures are well-known to provide a series of important challenges to the theory of tense. Unsurprisingly, they raise questions for the theory of space inflection as well. There is much more to be learned about the interpretation of embedded clauses in Nez Perce before final conclusions are drawn. In this section I present the present state of knowledge about embedded space inflection, with the understanding that it is incomplete.

There are two major strategies in Nez Perce that correspond to what we might think of as 'clausal embedding'. The first is a nominalizing strategy. The nominalized verb takes a participial form that may contain derivational morphology, such as applicatives, but may not contain aspect, tense or space inflection.

$$
\begin{array}{lll}
\text { kii-'u we waaqo' 'iin ke-m 'iin-e } & \\
\text { here-EMPH be now } & 1 \mathrm{SG} \text { REL-2SG } & 1 \mathrm{SG}-\mathrm{OBJ} \\
\text { wawloq-sa-m-qa } & \text { payn-óo-t'as 'im-ené } \\
\text { want-IMPERF-CIS-REC.PAST come-APPL-PART you-OBJ }
\end{array}
$$

Here am I, who you wanted to come to you (Aoki and Walker 1989: 253)

The absence of aspect, tense and space inflection in nominalizations suggests that these structures are syntactically smaller than full finite clauses.

The second clausal embedding strategy embeds a full finite clause with no restrictions on the morphology of the embedded verb. There are typically no morphological marks of embedding. This can make a difference between quotation (direct discourse) and embedding (indirect discourse) very difficult to diagnose. ${ }^{22}$ To study space inflection in embedded clauses, we will need to look at clauses that we are sure are embedded, not quoted. One way we can recognize such clauses is to look for indexicals to the utterance situation. In (32), the complement of the verb cuukwe 'know' contains two indexicals that derive their reference from the utterance situation: kine 'here' and 'ee 'you'. If the lower clause were quoted, by contrast, we would expect all indexicals in it to the determined from the point of view of the dog's owners, the "speakers" of the quote.

(32) Context: a woman scolds a dog that has wandered out into the street.

$$
\begin{array}{lll}
\text { ciklii-n! calewí yox-ma hi-pe-cuukwen-u' kine 'iskit-pe } \\
\text { go.home-IMPER if dem-PL 3SUBJ-S.PL-know-FUT here road-LOC }
\end{array}
$$

Space marking is restricted by verb class in Sanuma, and space markers can form idioms with verbs that exclude subjects (p. 165). This may suggest that space marking is syntactically low in Sanuma. Parallel data for tense are not available.

${ }^{22}$ This task is complicated by a cultural preference for direct discourse among Nez Perce speakers (Aoki 1979, Cash Cash 2005). 
'ee wees, imaa-'nahci'watk-o' 'ee

you be-IMPERF, 2SG.REFL-get.in.trouble-FUT you

Go home! if they find out you are here in the road, you will get in trouble!

A diagnostic that is not available to diagnose embedding is sequence of tense, i.e. tenses in embedded clauses which are in some way 'copied' from the higher clause and are not semantically interpreted. Tenses in embedded clauses seem to always match the tense that would be used in a quote. In both cases following, the embedded clause is present tense; recall that present is not overtly marked.

(33) Context: It is summer. I have just watched a video that my grandmother recorded in the winter. I describe it to you:

hi-hi-ne kona hii-we-s 'enim

3SUBJ-Say-PERF there 3SUBJ-be-IMPERF winter

She said it was winter there

weet'u hi-cuukwe-c-i-ne kii wi-s-iix

NEG 3SUBJ-know-IMPERF-S.PL-REM.PAST this be-IMPERF-S.PL

peqiyex piyee-pim miya'c.

nephew brother-GEN child

They didn't know that this was their nephew, their brother's child. (Aoki and Walker 1989: 374)

Example (33) can be considered embedding based on our indexical diagnostic; kona 'there' gives a spatial relation from a deixis point grounded in the speech situation. Our diagnostic does not clarify whether example (34) involves embedding. However, the sentence reports knowledge that the subject of the matrix verb did not have; if the lower clause were quoted, it is not clear to whom the quote is being ascribed.

Space markers in embedded clauses may also take the form that would be used in a quote. ${ }^{23}$ In the following case, we have an embedded clause, as diagnosed by the utterance-deixis of kinix 'from here'. The cislocative locates the endpoint of the car's path proximal to the policeman, not to the speaker of (35).

(35) Context: We are in Lapwai. A policeman is stationed 3 miles to the north in Spalding. A speeding car from the direction of Lapwai comes towards him.

inpeweet hi-hi-ne naqc aatamoc kin-ix hamti'c-nix

policeman 3SUBJ-say-PERF one car here-from fast-EMPH

hi-ku-sa-m-qa

3SUBJ-go-IMPERF-CIS-REC.PAST

The policeman said that a car had been coming toward him from here very quickly.

\footnotetext{
${ }^{23}$ However, there is less data available on embedded space inflection than on embedded tense. This is because embedded clauses typically lack space marking; recall that the lack of space marking is spatially neutral.
} 
Interestingly, in this case, the independent spatial adverbial kinix 'from here' and the cislocative space marker differ in their point of deixis. The former is deictic to the location where (35) is uttered (Lapwai); the latter is deictic to the location where the policeman utters his report (Spalding).

There is some evidence that space markers and tense markers are not the only Nez Perce indexicals that can resolve their indexicality otherwise than by reference to the overall context of utterance. Just as we find tenses and space markers 'shifting' to mark time and space from, as it were, the perspective of the subject of the embedding verb, we also find 'shifty' person indexicals. ${ }^{24}$ In the following case, we know that the embedded clause is not a quote due to the indexical kona 'there' which marks spatial distance with respect to the utterance situation. Nevertheless, the first person subject of the embedded verb 'eneesepesukse refers not to the speaker of (36), but to the speaker of the reported speech act, here my friend. (A note on morphology: the morpheme ' $e$ is only used for a third person object in the presence of a first or second person subject. A third person subject would have produced the form hineesepesukse.)

(36) Context: We are not at the Cafe; I am reporting on the activities of my friend who is there.

hi-hi-ne oykalo-na ke kona hi-w-s-iix iwepne

3SUBJ-Say-PERF everyone-OBJ REL there 3SUBJ-be-IMPERF-S.PL wife

'e-nee-sepesuk-se

3OBJ-O.PL-introduce-IMPERF

He said he's introducing his wife to everyone who's there.

Just as in (35), the indexical elements of the lower clause of (36) differ in deictic perspective. The first person-'the speaker in the context'-relies on the context of the reported speech act. The spatial adverbial kona 'there'-'a location distant from the location of the context'-relies on the matrix context.

We have seen a case where space inflection draws its value from the context of a reported speech act, but an independent spatial indexical draws its value from the matrix context, (35). What can such cases tell us about the semantics of space markers? Anand and Nevins (2004) propose that shifty indexicals are constrained in their abilities to draw values from what look like different contexts. Based on facts from Zazaki and Slave, they argue that in an embedded clause, all indexicals that rely on a particular contextual parameter will have to use the same value for that parameter. ${ }^{25}$ Thus in Slave, if one first person indexical in the complement of a speech verb is 'shifty', referring to the subject of the speech verb, all other first person indexicals in the embedded clause must be shifty as well.

On this view, the fact that in (35) a spatial adverbial and a space marker are deictic to different spatial locations suggests that the two rely on different parameters of context. For instance, it might be that the spatial adverbial relies on the

\footnotetext{
${ }^{24}$ Several theories of indexical shifting have been put forward in the recent literature: Schlenker 1999, 2003, Stechow 2003, Anand and Nevins 2004.

${ }^{25}$ Following Kaplan (1989), a context may be thought of as a tuple of parameters for the speech act: its speaker, hearer, temporal location, spatial location, and so on.
} 
location parameter, whereas the locative meaning of the space inflection is derived via other parameters-for instance, the location of the speaker (speaker parameter) at the utterance time (time parameter). ${ }^{26}$

However, it is possible to use a shifty space marker even in cases where it does not seem that first person is shifty. In the following case, I have just seen the storekeeper say something along the lines of "They are bringing me food for my store." When I report his utterance, I use a cislocative marker to indicate spatial location/direction with respect to the location of the storekeeper and his utterance; the cislocative is shifty. However, I use third person pronouns where he used first person indexicals. (Thus the Nez Perce person marking matches the English translation.)

Context: I have been watching a TV news report about the aftermath of flooding in Iowa. A storekeeper in the flood zone is being interviewed, saying that his store is finally being restocked after the flood. You come in and I describe what has just happened:

itam'ya'waat hi-i-ca-qa

storekeeper 3SUBJ-Say-IMPERF-REC.PAST

pee-sepewihnen-uu-s-in-m hipt ip-nim itamyaanwaas-'ayn

3/3-bring-APPL-IMPERF-S .PL-CIS food 3SG-GEN store-for

The storekeeper was saying that they're bringing him food for his store.

Here third person is used both for the object of the embedded verb and for a possessor in the embedded clause. (We know that the object is third person due to the verbal prefix pee, which marks third person subject and third person object. The object itself is not overt.) Supposing that the cislocative draws its value from the speaker parameter and the time parameter of the context, we will need the speaker parameter for the embedded clause to pick out the storekeeper and the time parameter for the embedded clause to pick out the time of his uttering his sentence in the interview. This gets us the shifty cislocative. If the speaker parameter picks out the storekeeper, however, we would expect him to be referred to in the first person. In Nez Perce, like in English, one does not go around referring to oneself in the third person. If we want to refer to the speaker in the context, a first person indexical must be used. The fact that first person is not used in this case suggests that the speaker contextual parameter has not been shifted. Nonetheless, the cislocative has.

This evidence suggests that whatever the internal representation of space markers-whether they are deictic to the utterance location, or to the location of the speaker at the utterance time-they must be allowed to shift independently of both first person indexicals and other spatial indexicals. It does not seem likely that this is because just any combination of shifty and non-shifty indexicals is allowed

\footnotetext{
${ }^{26}$ Indeed it has been proposed that spatial deixis is generally determined not with respect to the utterance location, but with respect to the speaker's location (at a particular time) (Denny 1982, Anderson and Keenan 1985: 277.)
} 
in an embedded clause in Nez Perce. ${ }^{27}$ It could be because space markers draw their indexicality from some third, previously unknown parameter of context, say, location'. More interestingly, it could be because the analogy between shifty space inflection and shifty person indexicals in embedded clauses obscures a fundamental difference. There seems to be much more latitude about person indexical shifting than there is about tense and space inflection shifting. It could be that the shiftiness of space markers and tenses, which occupy a high region of the clausal spine, ensues from some kind of binding or abstraction required by the embedding verb (following the approach of Chierchia 1989, Abusch 1997, Stechow 2003 and many others), whereas person indexical shiftiness results from another, optional mechanism. These questions raised by embedded space markers are important and potentially have wide ramifications for the entire space marking semantics. I expect that they will prove crucial as the semantics of space markers are further investigated in ongoing work.

\section{Conclusion}

I have argued that Nez Perce space markers belong to a verbal inflectional category of space inflection. Space inflection, like tense, is a closed-class category whose members are (in matrix contexts) deictic to the utterance situation. I have proposed that space markers be treated, along with tenses, as situation modifiers. Space markers and tenses narrow the spatiotemporal coordinates of a topic situation with respect to the utterance situation.

I have also presented some preliminary findings regarding space inflection in embedded clauses. Investigations to date indicate that space inflection and tense inflection behave alike in embedded clauses in taking the same form that would be used in a quote. This obtains regardless of the shiftiness of other indexicals in the embedded clause. The nature of this shiftiness awaits further empirical investigation.

\section{References}

Abusch, Dorit. 1997. Sequence of tense and temporal de re. Linguistics and Philosophy 20:1-50.

Anand, Pranav, and Andrew Nevins. 2004. Shifty operators in changing contexts. In Proceedings of SALT XIV.

Anderson, Stephen, and Edward L. Keenan. 1985. Deixis. In Language Typology and Syntactic Description, ed. Timothy Shopen, volume III: Grammatical categories and the lexicon, 259-308.

\footnotetext{
${ }^{27}$ Specifically, when the embedded clause contains a non-shifty 2 nd person, it may not contain a shifty 1 st person. Thus when A tells me "I saw B" I can report this to B as "A $\mathrm{A}_{i}$ says he $_{i}$ saw you" but not as "A $\mathrm{A}_{i}$ says $\mathrm{I}_{i}$ saw you".
} 
Aoki, Haruo. 1970. Nez Perce grammar. University of California Publications in Linguistics. Berkeley: University of California Press.

Aoki, Haruo. 1979. Nez Perce texts. Berkeley: University of California Press.

Aoki, Haruo. 1994. Nez Perce dictionary. Berkeley: University of California Press.

Aoki, Haruo, and Deward Walker. 1989. Nez Perce oral narratives. University of California Press.

Bar-El, Leora. 2005. Aspectual distinctions in Skwxwú7mesh. Doctoral Dissertation, University of British Columbia.

van Benthem, J.F.A.K. 1977. Tense logic and standard logic. Logique et analyse 80:395-436.

Borgman, Donald M. 1990. Sanuma. In Handbook of Amazonian languages, ed. Desmond Derbyshire and Geoffrey Pullum, volume 2, 15-248.

Cash Cash, Phillip. 2005. ke yóx hitamtáaycaqa c'íiqinpa (that which is reported in talk): Reported speech in Nez Perce. In Coyote Papers XIII, 75-85. University of Arizona.

Chierchia, Gennaro. 1989. Anaphora and attitudes de se. In Language in context, ed. R. Bartsch et al. Foris.

Comrie, Bernard. 1985. Tense. Cambridge University Press.

Crook, Harold David. 1999. The phonology and morphology of Nez Perce stress. Doctoral Dissertation, University of California at Los Angeles.

DeCormier, Christopher. 1979. Kekchi particle čaq: relations in time and space. International Journal of American Linguistics 45:289-98.

Denny, J. Peter. 1982. Semantics of the Inuktitut (Eskimo) spatial deictics. International Journal of American Linguistics 48:359-384.

Kaplan, David. 1989. Demonstratives. In Themes from Kaplan, ed. Joseph Almog, John Perry, and Howard Wettstein, 481-564. Oxford: Oxford University Press.

Klein, Wolfgang. 1994. Time in language. London: Routledge.

Kracht, Marcus. 2002. On the semantics of locatives. Linguistics and Philosophy 25:157-232.

Kratzer, Angelika. 1995. Stage-level and individual-level predicates. In The generic book, ed. Gregory N. Carlson and Francis Jeffry Pelletier, 125-175. Chicago: The University of Chicago Press.

Kratzer, Angelika. 1998. More structural analogies between pronouns and tenses. In Proceedings of SALT VIII. CLC Publications.

Kratzer, Angelika. 2007. Situations in natural language semantics. In Stanford encyclopedia of philosophy, ed. E. Zalta, Winter 2007 edition. URL http://plato.stanford.edu/entries/situations-semantics/.

Kusumoto, Kiyomi. 2005. On the quantification over times in natural language. Natural Language Semantics 13:317-357.

Matthewson, Lisa. 2004. On the absence of telic accomplishments in St'át'imcets. In Proceedings of WSCLA 10, UBC Working Papers in Linguistics.

Mithun, Marianne. 1999. The languages of native North America. Cambridge University Press.

Morvillo, Anthony. 1891. Grammatica linguae numipu. Auctore presbytero mis- 
sionario e Soc. Jesu in Montibus Saxosis. Desmet, ID: Indian Boys' Press. O’Herin, Brian. 2002. Case and agreement in Abaza. SIL International.

Partee, Barbara. 1973. Some structural analogies between tenses and pronouns in English. Journal of Philosophy 70:601-609.

Phinney, Archie. 1934. Nez Percé texts. Columbia University Contributions to Anthropology. Columbia University Press.

Quine, W.V.O. 1960. Word and object. Cambridge, MA: MIT Press.

Reichenbach, Hans. 1947. Elements of symbolic logic. Berkeley: University of California Press.

Rude, Noel. 1985. Studies in Nez Perce grammar and discourse. Doctoral Dissertation, University of Oregon.

Schlenker, Philippe. 1999. Propositional attitudes and indexicality: a crosscategorial approach. Doctoral Dissertation, MIT.

Schlenker, Philippe. 2003. A plea for monsters. Linguistics and Philosophy 26:29_ 120.

Shaer, Benjamin. 2003. Towards the tenseless analysis of a tenseless language. In Proceedings of SULA 2, 139-156.

Stechow, Arnim von. 2003. Feature deletion under semantic binding: tense, person and mood under verbal quantifiers. In Proceedings of NELS 33, ed. Makoto Kadowaki and Shigeto Kawahara, 379-404. Amherst: GLSA.

Tonhauser, Judith. 2006. The temporal semantics of noun phrases: evidence from Guaraní. Doctoral Dissertation, Stanford.

Wiltschko, Martina, and Elizabeth Ritter. 2005. Anchoring events to utterances without tense. In Proceedings of WCCFL 25. Cascadilla. 